\title{
A Discrepancy in Teachers and Principals Perceptions of Educational Initiatives
}

\author{
Linder Ifat, Weissblueth Eyal ${ }^{*}$
}

Department of Physical Education, Ohalo Academic College of Education, Israel

Copyright $\bigcirc 2017$ by authors, all rights reserved. Authors agree that this article remains permanently open access under the terms of the Creative Commons Attribution License 4.0 International License

\begin{abstract}
The current study was set to examine the role of school principals in Israel in the professional development process of their teachers following the implementation of a new professional reform. 159 teachers and 13 principals responded to a questionnaire designed to collect data concerning the involvement of principals in initiatives developed by their teachers. Two main differences were found to be significant, with regard to principals' involvement in selecting the initiative's focus and in deciding its actual content. The results suggest that teachers and principals differ in their assessment of the principals' involvement in the developing initiatives. The reasons and implications for this discrepancy are discussed and elucidated.
\end{abstract}

Keywords Teachers, Professional Development, Principals, Educational Initiative

\section{Introduction}

The "Ofek Hadash" ("New Horizon") reform, which was first implemented in the Israeli education system in 2008, was a part of an employment agreement signed between the Israeli Ministry of Education (MOE) and the teachers' union. As a part of this reform, teachers' promotion was tied to their professional development, defining 10 levels of professional seniority and requiring teachers to go through training in order to be promoted. In this reform, teachers in levels 7-9 are now required to take specifically designed courses in universities and academic colleges, with the aim of developing education practitioners in various roles, both personally and functionally, in order to improve their performance. One of the advanced courses offered for teachers was designed to encourage educational entrepreneurship through the development of an innovative, relevant, and implementable initiative.

As a part of the course The Initiating and Implementing Teachers, which was offered by the Professional
Development Unit at Ohalo Academic College - an academic teachers' training institution in the north of Israel teachers were required to choose and develop their own educational initiative among various fields: a teaching plan; an intervention program; cultivating learning skills among students - in a specific subject or in general; an all-school program; programs for students' involvement in the community; and so on. Courses of this type were developed in other academic institutions as well, and were described in a previous research. According to the Ministry of Education's guidelines, the school principal should play a role in leading the professional development of their staff by planning and leading the learning and development processes, based on the teachers' wishes and professional needs at each stage of their professional educational career [1]. Yet, these guidelines did not include a specific set of actions required by the principals, leaving their role open for interpretation. In an attempt to translate the general guidelines into an action plan, a major institution for principals' professional development stated that one of the principal's roles is to lead the staff, manage it, and guide its professional development [2]. The document suggested a number of actions that should be considered by principals, such as encouraging teachers' pedagogical and educational initiatives, offering professional support and examples for developing these initiatives, and more.

The MOE's guidelines state that principals are expected to play a key role in several stages of their staff's professional development process: 1) Approving the course. The principal is required to sign the teacher's request for taking this course. Skilled principals recognize the potential of a specific teacher's professional development as a mean for empowering the entire school, particularly when a teacher is interested in a course which would help them develop a specific field within their school. Some principals encourage a small team of teachers to study together, in order to create a critical mass that would bring back the course's contribution into the school and embed its products. 2) Choosing the focus of the initiative. Principals may direct teachers to explore issues and initiate ideas that are of interest at their schools. 
3) Affecting the initiative's components. Principals can identify and mobilize collaborators and resources, and link the initiative to other activities at school. 4) Actual implementation of the initiative. Principals can allocate managerial attention for execution, finding relevant coworkers, acknowledging and respecting the initiating teacher, reflecting and assessing, etc.

Thus, when constructing the course's layout, it was assumed, based on the MOE's guidelines, that the principals influenced the teachers who were about to embark on their professional development courses by 1) directing them to select a particular course; 2) directing the choice of their initiative's focus; 3) guiding and supporting them in the development process; and 4) attaining the required resources (Figure 1).

As far as we know, there is no official number concerning the initiatives that had matured and were successfully implemented in schools following courses of this type, but a field discourse based on conversations with courses' supervisors suggests the number is relatively low. It seems that teachers experience difficulties in implementing their initiatives, whether it is due to a low level of personal skills, difficulties in finding collaborators, or the lack of support and backing by their principals. The current study focused on teachers' and principals' perceptions concerning these initiatives, and the discrepancies between them.

\section{Materials and Methods}

Quantitative methods were mainly used in the study with qualitative methods used in the preliminary stage.

\subsection{Research Population}

The population included 320 in-service teachers who participated in professional development courses and their
67 principals. All the 320 teachers were at relatively high development levels (6-9) and had around 20 years of professional experience. Mean age of all the 320 teacher participants: $50.4,(\mathrm{SD} \pm 9.5) .91 \%$ of them were women.

\subsection{Research Tools}

1. Semi-structured interviews with teachers and their principals [4] in a pre-study. The results of the interviews were then used as basis for the construction of the questionnaires.

2. A teachers' questionnaire included general questions about demographic background (age, gender, teaching subject, role in school, seniority) as well as questions aimed at assessing teachers' perceptions concerning the influence of their principal on their initiative development process.

3. A principals' questionnaire included questions aimed at assessing the principals' perceptions concerning their involvement in the initiative development process of their teachers.

Both questionnaires employed a Likert scale (1-5, 1- very little, 5 - very much), asking the participants to assess the level of principals' involvement in various stages. Sample questionnaire items are exhibited in table 1. Experts validated the questionnaires for content validity, and reliability was assessed by comparing results with interviews of randomly selected subjects.

\subsection{Process}

The study was approved by the college IRB. Interviews of randomly selected subjects were transcribed and analyzed. At the end of the course, all participants were asked to fill in their respective questionnaire after they were informed and consented to take part in the study. The same was done with the school principals within a month period starting at the end of the course.

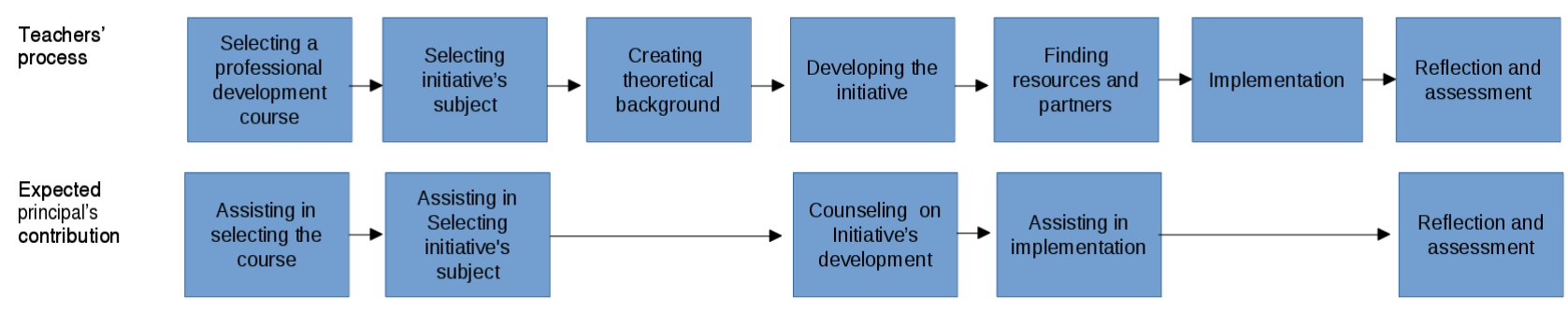

Figure 1. Teachers' professional development process and principals' expected contribution.

Table 1. Sample of questionnaire items

\begin{tabular}{|ll|}
\hline 1) & To what extent did your school principal know what initiative you were developing? \\
\hline 2) & To what extent did the principal direct the selection of your initiative topic? \\
\hline 3) & To what extent was the principal of the school a consultant for you in the content area of the initiative? \\
\hline 4$)$ & To what extent did the principal assist you in recruiting partners (both inside and outside the school)? \\
\hline
\end{tabular}




\subsection{Data Analysis}

Data from the questionnaires were analyzed with SPSS version 21 and included descriptive and inferential statistics: Student $\mathrm{t}$-test and factorial ANOVA when needed where $\alpha$ level was set to 0.05 .

\section{Results}

Out of the research population of 320 teachers and 67 principals, the questionnaires were completed by 159 teachers and 13 principals. Out of the participants, 53\% were elementary school teachers, $42 \%$ were teachers in junior-high schools, and 5\% were kindergarten teachers. $44 \%$ were in level 6-6.5 out of 9 in their professional development, $38 \%$ level $7-7.5$, and $18 \%$ were level 8 or higher. The mean age among teachers was 50.5 , with 25.9 years of experience as teachers in 30 different disciplines. The average work experience among principals was 9.2 years. Further details are exhibited in table 2.

Table 2. Teachers and principals: age and experience data.

\begin{tabular}{|c|c|c|c|c|c|c|}
\hline Function & Parameter & $\mathrm{N}$ & Minimum & Maximum & Mean & $\mathrm{SD}$ \\
\hline \multirow{2}{*}{ Teacher } & Age & \multirow{2}{*}{159} & 21 & 65 & 50.5 & 6.7 \\
\cline { 2 - 5 } & Years at work & & 10 & 42 & 25.9 & 6.0 \\
\hline \multirow{2}{*}{ Principal } & Age & \multirow{2}{*}{13} & 42 & 67 & 50.2 & 6.8 \\
\cline { 2 - 7 } \cline { 5 - 7 } & Years at work & & 2 & 40 & 9.2 & 9.9 \\
\hline
\end{tabular}

\section{Differences between Teachers' and Principals' Perspectives}

When comparing the perspectives of teachers and principals, two main differences between the teachers and the principals' assessment were found to be significant: Concerning the principals' involvement in selecting the focus of the initiative, and their involvement in the initiative's content (Table 3).

An independent-samples t-test was conducted to compare teachers' $(\mathrm{M}=4.08, \mathrm{SD}=1.08)$ and principals' $(\mathrm{M}=2.69$, $\mathrm{SD}=1.44$ ) assessments concerning the extent to which the principal was involved in selecting the focus $(\mathrm{t}(13)=3.39$, $p=0.005)$. These results suggest that while the teachers felt their principals were involved in selecting the focus of their initiative, the principals felt less involved in the process. Another independent samples t-test was conducted to compare teachers' $(\mathrm{M}=2.28, \mathrm{SD}=1.58)$ and principals' $(\mathrm{M}=3.38, \mathrm{SD}=1.39)$ assessments concerning the extent to which the principal was an advising factor in the initiative's content $(\mathrm{t}(15)=-2.74, \mathrm{p}=0.015)$. These results suggest that while the principals felt they were involved in advising regarding the project's content, the teachers assessed the principals' involvement as less significant. Specifically, our results suggest that teachers' perceptions of their principal's function differed significantly from what their principals perceived it to be. Thus, the principals' involvement was perceived differently by the teachers and by their principals (Figure 2).

Table 3. Principals' contribution to the teachers' development process as assessed by principals and teachers (Means \pm SD) $* * * p=0.005, * * p=0.015$

\begin{tabular}{|c|c|c|}
\hline Principals' contribution & $\begin{array}{c}\text { Assessment by } \\
\text { principals }\end{array}$ & $\begin{array}{c}\text { Assessment by } \\
\text { teachers }\end{array}$ \\
\hline $\begin{array}{c}\text { Selecting a professional } \\
\text { development course }\end{array}$ & $2.72 \pm 1.64$ & $1.86 \pm 1.71$ \\
\hline $\begin{array}{c}\text { Assisting in Selecting subject } \\
\text { for the initiative }\end{array}$ & $2.69 \pm 1.44$ & $4.08 \pm 1.08 * * *$ \\
\hline $\begin{array}{c}\text { Counseling on Initiative's } \\
\text { development }\end{array}$ & $3.38 \pm 1.39$ & $2.28 \pm 1.58^{* *}$ \\
\hline $\begin{array}{c}\text { Assisting in resources and } \\
\text { partners' recruitment }\end{array}$ & $3.54 \pm 1.45$ & $2.74 \pm 1.57$ \\
\hline
\end{tabular}

Both teachers and principals reported a low to mid level of principals' involvement in the professional development processes. However, differences were found in the assessment of the stages in which the principals were involved. While the teachers felt that their principals were more involved in selecting the topic and less involved in the initiative's content, the principals reported the opposite namely, that they were less involved in choosing the topic and more involved in content. Insignificant differences were found between teachers' and principals' assessment concerning the principals' involvement in selecting the professional development course $(\mathrm{M}=1.86, \quad \mathrm{SD}=1.71$; $\mathrm{M}=2.72, \mathrm{SD}=1.64$ respectively) and in allocating resources and partners $(\mathrm{M}=2.74, \quad \mathrm{SD}=1.57, \quad \mathrm{M}=3.53, \quad \mathrm{SD}=1.45$ respectively). It seems that while principals maintained that they moderately directed and assisted the teachers, the teachers felt that the principals' involvement in these areas was low.

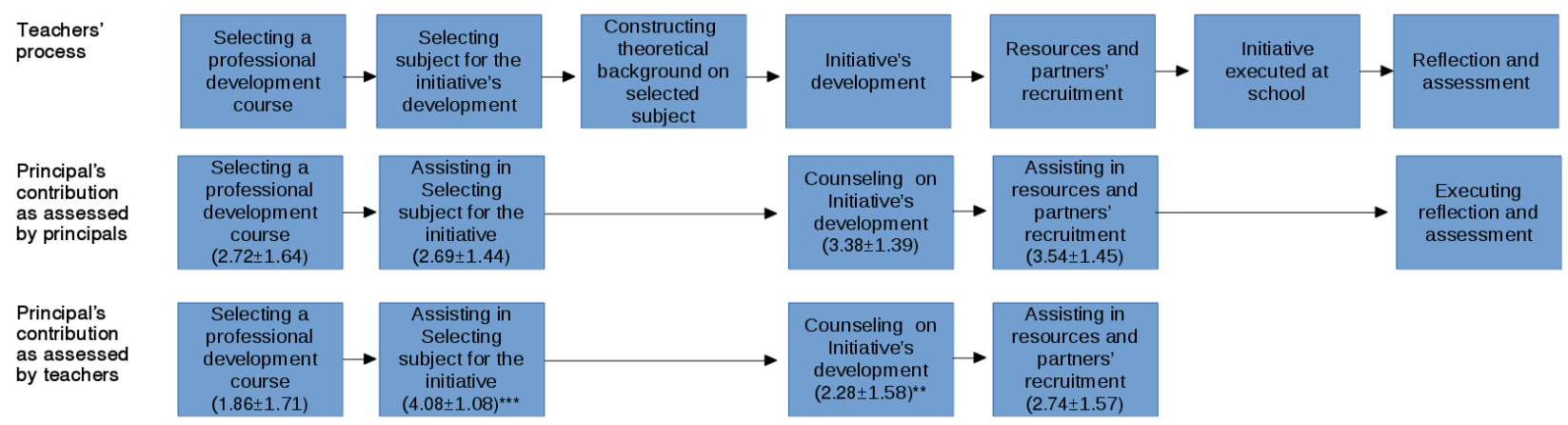

Figure 2. Principals' contribution to the teachers' development process as assessed by principals and teachers (Means $\pm \mathrm{SD}$ ) ${ }^{* * *} \mathrm{p}=0.005, * * \mathrm{p}=0.015$ 


\section{Discussion}

While the MOE guidelines allocate an important role for school principals in the professional development of their teaching staff, both teachers' and principals' assessments of the principals' involvement in the process suggest that reality might be different. In three out of the four stages examined in the study, the principals' assessment of their own involvement was higher than that of the teachers. This may be explained by the fact that principals are aware of the MOE guidelines and expectations, and tend to overestimate their involvement in the process in order to maintain their image.

But how can we explain the lack of principals' involvement in the professional development of their students? A number of reasons can be offered here. First, it is possible that the principals do not understand the potential contribution of this kind of professional development to their schools. A formal report by the Keystone Institute in Israel, advising to the MOE, explicitly defined the role of school principals in Israel as "encouraging pedagogical initiatives and education of teachers, and providing professional support for their planning, implementation and improvement in the classroom, school and community..." [3]. Yet, even in such an explicit report, there are no specific references or guidelines on how to implement this idea with the school's goals in mind. The support of the principals is seen, in this context, as part of their job to nurture and invest in human capital (a worthy goal in its own right, without doubt). However, it does not provide a clearer method of linking the educational initiative created by the individual teacher with the policy development processes of their school. Second, the low level of involvement may stem out of inadequate training for principals on how to guide, advise, and support their teachers in their professional development process. Bolam [5] argues that professional development should be considered a long and active process, in which principals and teachers act together to improve their work. In this context, the importance of this domain and the expectation for principals' involvement are specifically highlighted. Many studies [5]-[9] highlighted the role of the principals as responsible for the professional development of their teaching staff. Oplatka [9] noted that there is a lack of theoretical framework for the principal's work, and that in its absence, diverse ways of preparing and training principals exist. Thus, principals may take a number of different approaches. Third, it is possible that principals tend to prioritize other tasks and neglect their duty to guide their developing teachers due to work overload. Castle et al. [10] found that a principal is required to handle five key missions at the same time: Coordinating system administrative tasks; management and monitoring current events at school; building relationships and school community; intervention and assistance in special problems of students, teachers' assessment, and professional support (including professional development); and directing school action. These tasks necessarily require prioritization, and it seems that the task of overseeing teachers' development process was not highly prioritized by most principals. It was noted [6] that while the goals and nature of the professional training is set by the MOE, its relevancy to the teacher should be examined by the teacher and the principal. We believe that in the spirit of the MOE's guidelines, principals should be aware of the professional development needs of their teachers and develop an organizational environment that supports their actions. The support of the principal is required not only in selecting the courses taken by the teachers, but also during the course and after it. Support must be expressed via the awareness of the necessary changes in the curricula, their implementation, and by allowing the teachers to continue their learning in school [7]. Additionally, we assume that expressions of personal attention such as attentiveness, consultation, support, and so on by the principals toward the trained teacher may give teachers the feeling that they are an important asset to the school organization and thereby encourage the learning by the teachers themselves. This assertion was not tested in the current study, and may be the focus of a future study.

\section{Study Limitations}

The current study design holds several limitations: 1) A limited rate of responses from principals. 2) Study population represented only the north-central and north-eastern regions of the country. 3) Lack of sufficient sectoral (urban, rural, religious, etc.) homogeneity of schools from which teachers and principals were sampled. 4) Study participants have varied levels of education.

\section{REFERENCES}

[1] Dressler M., Sela L., Arenberg R., Mazor S. We were dreamers - initiating and operating: Level 7 professional development for science and technology teachers, "The initiating and implementing teachers". Eureka, 37. https://www.matar.tau.ac.il/wp-content/uploads/2015/02/new spaper37docs10.pdf (2014, accessed 28 March 2017).

[2] MOE. Professional development of education practitioners as part of Ofek Hadash, policy and guidelines for the school year 2014-2015

https://docs.google.com/a/mypisga.org/viewer?a=v\&pid=site s\&srcid=bXlwaXNnYS5vcmd8bWFjaHNhbnxneDoxMTJh ODVkNzhmZWRkOTQ4 (2013, accessed 12 January 2015).

[3] Adler H. The principal's perception of his role in the state of Israel: A professional committee report for the creation of recommendation to the Ministry of Education. Keystone Institute, Jerusalem: Avney Rosha, 2008.

[4] Arksey H, Knight PT. Interviewing for social scientists: An introductory resource with examples. SAGE, 1999. 
[5] Bolam R. Professional Development and Professionalism. In: The principles and practice of educational management. London: SAGE, 2002, pp. 103-118.

[6] Aderet A. The Teacher as a Social Entrepreneur. Kibbutzim College 2012; Education and Context: 113-126.

[7] Avdor S. Outline for professional development of education practitioners in higher tanks 7-9 as part of Ofek Hadash $\mathrm{http}: / / \mathrm{cms}$.education.gov.i1/NR/rdonlyres/A8053F6E-CA944FDC-B00A-6F0824922187/153695/79.pdf (2015, accessed 12 January 2015).
[8] Karstanje P, Villa A, Villardon L. New Heads in Five Countries. In: New heads in the new Europe. New York: Waxmann Verlag, 2000, pp. 13-42.

[9] Oplatka I. Foundations of Education Management: Leadership and management in the educational organization. Haifa: Pardes, 2010

[10] Castle J, Mitchell C, Gupta V. Roles of elementary school principals in Ontario: Tasks and tensions. In: The role of the principal in Canada. Calgary: AB: Detselig, 2002, pp. 23-37. 